Jianxun Liu, Ning Li, Meirong Chen, Jianping Yang, Biao Long and Zhishen $\mathrm{Wu}^{\star}$

\title{
Durability of basalt fiber-reinforced polymer bars in wet-dry cycles alkali-salt corrosion
}

https://doi.org/10.1515/secm-2018-0030

Received January 22, 2018; accepted August 3, 2018; previously

published online November 20, 2018

\begin{abstract}
Basalt fiber-reinforced polymer (BFRP) bars have been increasingly applied to offshore structures, which are subjected to seawater corrosion and wet-dry cycles during their service time. This study evaluated the alkali-salt resistance performance of BFRP bars with different resin matrix types under wet-dry cycles. The tensile and shear strength of BFRP bars were tested. As a comparison, experiments of BFRP bars under continuous immersion were also conducted. The mechanisms of the two different conditions were analyzed by scanning electron microscopy (SEM). A relationship was established between the degradations under continuous immersion and wet-dry cycling. The results demonstrated that the alkali-salt resistance of vinyl resin matrix BFRP bars was superior to that of epoxy resin matrix BFRP bars under wet-dry cycles. Furthermore, according to the data obtained under continuous immersion, a time shift factor for predicting the durability of BFRP bars under wet-dry cycles was proposed.
\end{abstract}

Keywords: alkali-salt corrosion; basalt fiber; BFRP bars; shear properties; wet-dry cycling.

\section{Introduction}

Offshore structures are usually threatened by a series of problems owing to steel corrosion. Fiber-reinforced polymer (FRP) bars, as a type of corrosion-resistant material, have the advantages of light weight and high strength.

\footnotetext{
*Corresponding author: Zhishen Wu, International Institute for Urban Systems Engineering, Southeast University, Nanjing 210096, China; and School of Civil Engineering, Southeast University, Nanjing 210096, China, e-mail: zswu@seu.edu.cn Jianxun Liu: International Institute for Urban Systems Engineering, Southeast University, Nanjing 210096, China; and National and Local Unified Engineering Research Center of Basalt Fiber Production Application Technology, Southeast University, Nanjing 210096, China

Ning Li and Biao Long: School of Civil Engineering, Southeast University, Nanjing 210096, China

Meirong Chen and Jianping Yang: National and Local Unified Engineering Research Center of Basalt Fiber Production Application Technology, Southeast University, Nanjing 210096, China
}

ӘOpen Access. (c) BY (c) 2019 Walter de Gruyter GmbH, Berlin/Boston
They have become an alternative to steel reinforcement in concrete [1-4]. Traditional fibers used in FRP bars include carbon and glass fibers. Glass fibers are more extensively used owing to their low cost [5]. In recent years, basalt FRP (BFRP) has been developed as a result of its superior performance. It has higher cost efficiency than glass FRP (GFRP) [6-8]. Basalt fibers are produced directly from volcanic rocks without any additives, and are environmentally friendly, non-hazardous materials with rich raw material resources $[9,10]$.

Due to the harsh environments in offshore engineering structures, a large number of researches have been conducted on the durability of FRP bars [7, 11-14]. Serbescu et al. [15] tested the tensile properties of different types of BFRP bars under various accelerated conditions and proposed a methodology for predicting the long-term design strength of BFRP bars. The strength of BFRP bars was estimated to be retained by more than $72 \%$ after 100 years of exposure to concrete and mortar. Wu et al. [16] investigated the degradation, short-beam tests, and moisture absorption weighing of BFRP bars under alkaline conditions. The results indicated that, compared to GFRP bars in the literature, BFRP bars exhibited relatively high resistance to alkaline corrosion, maintaining more than $60 \%$ of their original strength at $55^{\circ} \mathrm{C}$ in the alkaline solution after 9 weeks. Compared to GFRP bars under similar alkaline conditions, BFRP bars exhibited a similar degradation rate during the initial stage, but the tensile strength and strength retention remained higher with the time. However, most of the corrosion processes in the laboratory are simulated by continuous immersion in a corrosive solution. Only a few scholars have studied FRP degradation under wet-dry cycles. For example, Al-Salloum et al. [17] reported that GFRP bars exhibited only a small decline in strength of less than $10 \%$ after 18 months of wet-dry seawater cycling. In the actual marine environment, BFRP bars are subjected not only to seawater, but also to erosion of the pore water in the concrete. The corrosion condition of accelerated testing is not enough to simulate the actual action. To the best of the authors' knowledge, only a few studies have been conducted on the durability of BFRP bars in wet-dry seawater cycles. The actual service condition of BFRP bars is the alkali-salt coupling environment. Furthermore, although wet-dry cycling tests can precisely simulate the true effect of seawater on the 
regional structure of tidal splashing, it is difficult to carry out such experiments because of the limitation of the laboratory conditions. Because the continuous immersion test is easy to carry out, the durability of FRP in the tidal splash area will be greatly simplified if the durability of the wet-dry cycle can be predicted by the durability under continuous immersion.

In order to solve the shortage of the existing literature, in this study, the durability of BFRP bars in an alkali-salt solution under wet-dry cycling and continuous immersion was studied comprehensively. The degradation of BFRP bars after corrosion is discussed and analyzed, and the mechanism is clarified by scanning electron microscopy (SEM). Furthermore, time shift factors are proposed to predict the durability of BFRP bars under wet-dry cycles according to the continuous immersion data. This study can provide data support for the application of BFRP in marine engineering.

\section{Materials and methods}

\subsection{Materials}

The basalt fibers used in this study were provided by Zhejiang GBF Basalt Fiber Co., Ltd. (Hengdian, China). The monofilament diameter was $13 \mu \mathrm{m}$, with a density of $2.65 \mathrm{~g} / \mathrm{cm}^{3}$. Three types of matrix resin were used in this study, namely DSM430 vinyl resin (Jinling DSM Resin Co.,
Ltd., Nanjing, China), E51 epoxy resin (Baling Petrochemical Co., Ltd., Guangzhou, China), and MFE-9 vinyl resin (Sino Polymer, Co., Ltd., Shanghai, China ), which are usually used in research. The properties of the matrix resins are listed in Table 1. The BFRP bars in this study were produced by the Green Material Valley (GMV) New Material Technology Co., Ltd. (Zhenjiang, China). The fiber volume fraction of the BFRP bars was approximately $65 \%$. The epoxy resin matrix BFRP bars were solidified at $160^{\circ} \mathrm{C}$ for $2 \mathrm{~h}$.

The three types of BFRP bars can be classified into two categories: epoxy vinyl resin matrix (vinyl resin) and bisphenol A epoxy resin matrix. In this study, the curing agent of epoxy vinyl resin matrix was benzoyl peroxide + tert-butyl peroxy-2-ethylhexanoate + benzoyl peroxide tert-butyl ester. The curing agent of epoxy resin matrix was methyl tetrahydrophthalic anhydride (MTHPA) (Runxiang Chemical Co., Ltd., Changzhou, China). The molecular formulae for the vinyl and epoxy resins are illustrated in Figures 1 and 2, respectively.

In order to simulate the concrete environment in seawater, based on the laboratory alkali solution erosion formula in ACI440.3R-04 [18] and artificial seawater solution formulations, $\mathrm{MgCl}_{2}$ was replaced with $\mathrm{NaCl}$, and $\mathrm{Na}_{2} \mathrm{SO}_{4}$ was removed in the artificial seawater solution in order to avoid an ion reaction between the alkali and simulated seawater solutions. The compositions of the alkali-salt mixture solution are displayed in Table 2, and the $\mathrm{pH}$ value of the solution at $55^{\circ} \mathrm{C}$ is 12.82 .

Table 1: Properties of matrix resins used in this study.

\begin{tabular}{lrrrrr}
\hline Resin & $\begin{array}{r}\text { Density } \\
\left(\mathbf{g} / \mathbf{c m}^{\mathbf{3}}\right)\end{array}$ & $\begin{array}{r}\text { Elastic modulus } \\
(\mathbf{G P a})\end{array}$ & $\begin{array}{r}\text { Elongation at } \\
\text { break (\%) }\end{array}$ & $\begin{array}{r}\text { Glass transition } \\
\text { temperature }\left({ }^{\circ} \mathbf{C}\right)\end{array}$ & $\begin{array}{r}\text { Moisture } \\
\text { absorption }(\%)\end{array}$ \\
\hline DSM430 & 1.07 & 2.98 & 3.35 & 121 & 0.36 \\
E51 & 1.10 & 3.44 & 2.87 & 130 & 0.52 \\
MFE-9 & 1.07 & 2.93 & 5.38 & 118 & 0.42 \\
\hline
\end{tabular}<smiles>C=C(C)C(=O)OCCCCOc1ccc(C(C)(C)c2ccc(OCCCOC(=O)C(=C)C)cc2)cc1</smiles>

Figure 1: Molecular formula of vinyl resin.<smiles>CC(C)(c1ccc(OCC(O)COc2ccc(OCC3CO3)cc2)cc1)c1ccc(OCC2CO2)cc1</smiles>

Figure 2: Molecular formula of bisphenol A epoxy resin. 
Table 2: Chemical compositions of artificially simulated alkali-salt solution.

\begin{tabular}{lllllll}
\hline Component & $\mathrm{Ca}(\mathrm{OH})_{2}$ & $\mathrm{KOH}$ & $\mathrm{NaOH}$ & $\mathrm{NaCl}$ & $\mathrm{CaCl}_{2}$ & Deionized water \\
\hline Content & $118.5 \mathrm{~g}$ & $4.2 \mathrm{~g}$ & $0.9 \mathrm{~g}$ & $30.88 \mathrm{~g}$ & $1.16 \mathrm{~g}$ & $1000 \mathrm{~g}$ \\
\hline
\end{tabular}

\subsection{Test setup}

A Donghua SJY-III acid salt corrosion test chamber (Suzhou, China) and a Sanfa DHG-9101-2SA electric heating oven (Shanghai, China) were used for the continuous immersion test and the wet-dry cycles tests. For the wetdry cycles test, with reference to actual tidal activities, the duration of one cycle was set at $24 \mathrm{~h}$ (immersed in corrosive solution for $12 \mathrm{~h}$ and dried in the oven for another $12 \mathrm{~h})$.

In the tensile test, the ends of the BFRP bars were anchored with a $30 \mathrm{~cm}$ seamless steel pipe filled with epoxy resin. The length of the free stretch part was $40 \mathrm{~cm}$, as shown in Figure 3. In the shear strength test, the specimen length was $30 \mathrm{~cm}$. There were five specimens in each test group. The name of a specimen was divided into three parts. The first part was the resin type, where BDSM, $\mathrm{BE}$, and BMFE were named as BFRP bars with DSM430, E51, and MFE-9 resins, respectively. The second part represented the corrosion condition, where DW was wet-dry cycling and $\mathrm{CI}$ was continuous immersion. The third part was the age of corrosion (in days). For example, BDSM-DW21 means a BFRP bar corrosion for 21 days under wet-dry cycling with DSM430 resin. The diameters of BDSM, BE, and BMFE were $5.79,5.87$, and $5.77 \mathrm{~mm}$, respectively.

The tensile strength was conducted using the LFV1000-HH tester produced by Walter+Bai AG Testing Machines (Switzerland), as shown in Figure 4. The maximum static test load of the tester was $1000 \mathrm{kN}$ and the accuracy level was $5 \%$. The shear strength test was conducted using the AG-X test machine produced by Shimadzu company (Japan). The maximum static test load was $10 \mathrm{kN}$ and the accuracy level was 5\%. The shear strength test device consisted of three parts, as shown in Figure 5. The BFRP bars threaded the metal sleeve and passed through the base pipes. The diameters of the through-holes and metal sleeve inner diameter were $8 \mathrm{~mm}$,

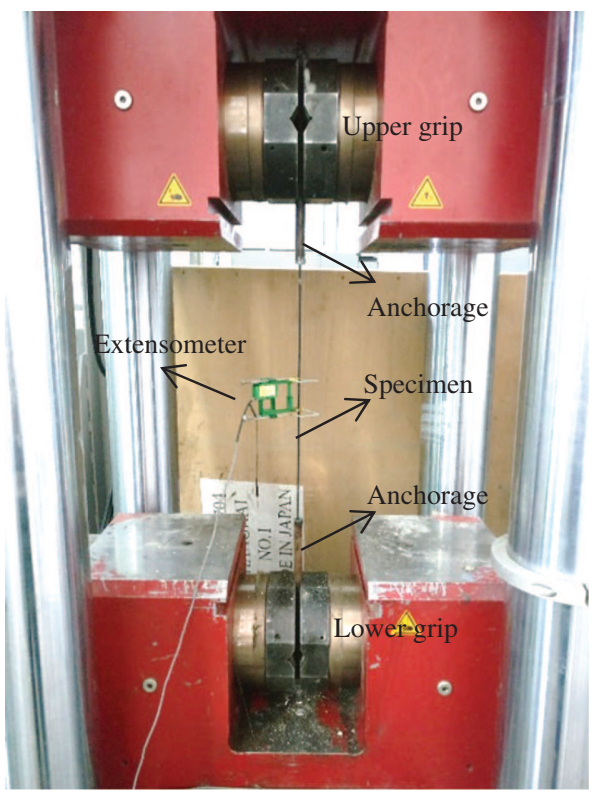

Figure 4: Tensile test equipment.

which was slightly larger than that of BFRP bars. The distance between the width of the cover plate and the through-hole was $10 \mathrm{~cm}$. The shear force was loaded from the test machine through the cover plate.

SEM analysis was conducted using an SEM-SERVO high temperature in situ fatigue testing machine produced by Shimadzu Company (Japan). The specimen was cut into small pieces after reaching the required age. After cleaning and drying, the fracture part of the BFRP bars was bonded to the small metal sheet and sprayed with gold. The prepared sample was observed to judge the bonding status between fibers and resins.

\subsection{Aging procedure}

In order to accelerate the BFRP degradation in the alkalisalt solution, both continuous immersion and wet-dry

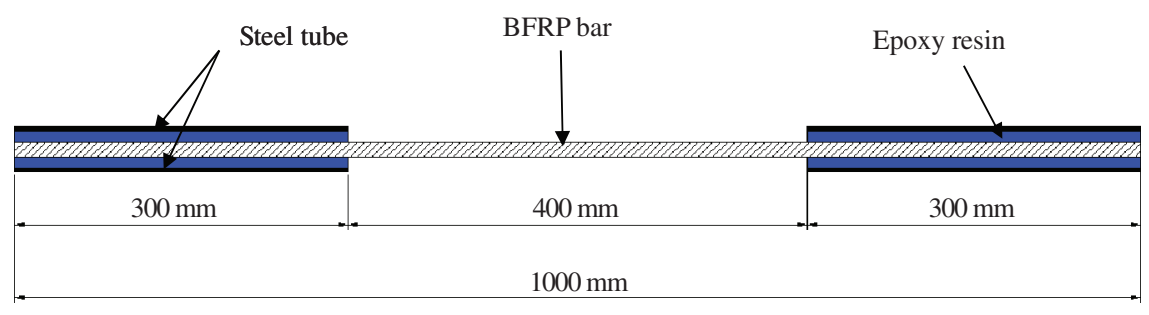

Figure 3: Tension test specimen. 
$\mathbf{A}$

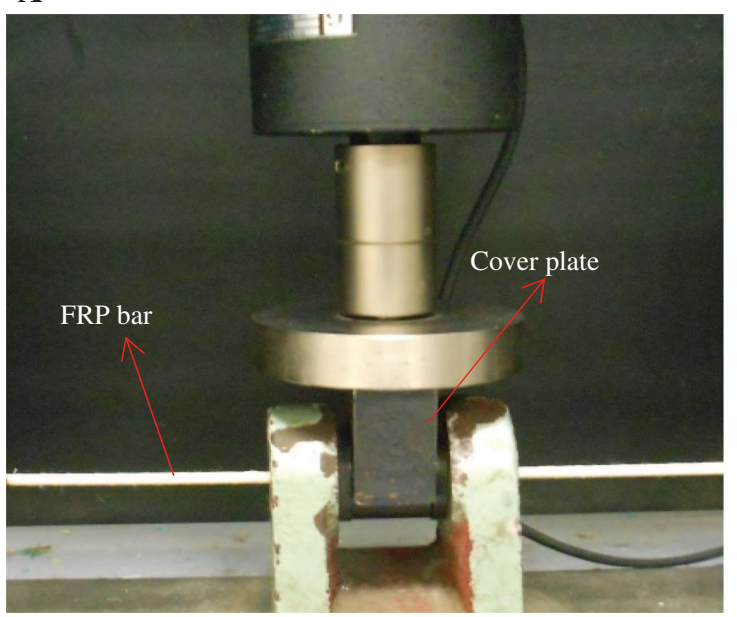

B

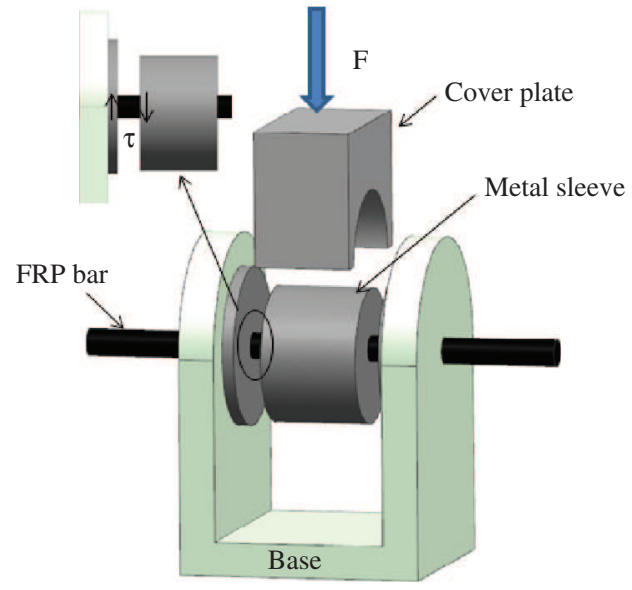

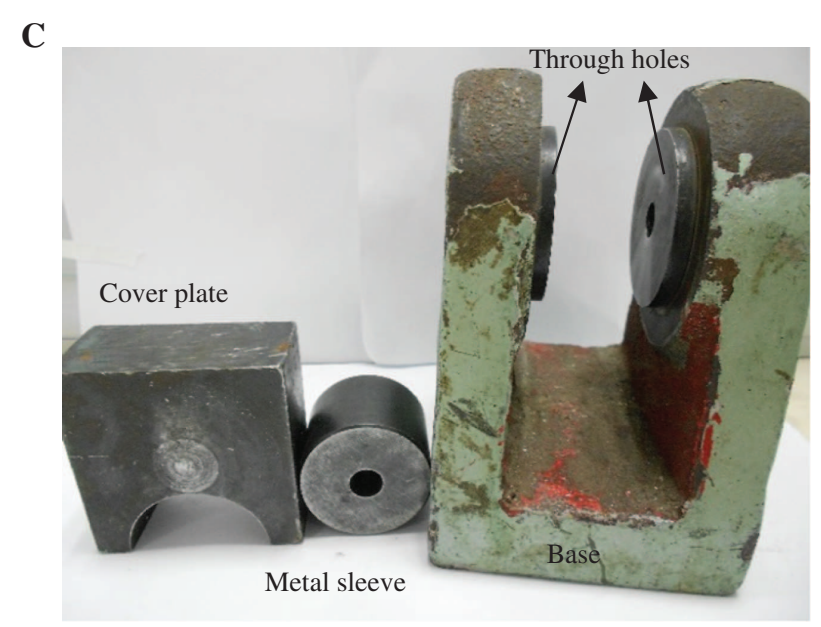

Figure 5: Shear test equipment: (A) photograph; (B) schematic sketch; (C) components.

cycling corrosion were conducted at $55^{\circ} \mathrm{C}$. Based on previous research [19], the corrosion ages were set to 21,42 , and 63 days. After aging, the specimens were thoroughly cleaned and dried.

\subsection{Loading procedure}

Based on ACI 440 3R-04 [18], the displacement-controlled loading method was adopted for the tensile experiment and the loading rate was $2 \mathrm{~mm} / \mathrm{min}$. The strain of the bars was measured by an extensometer with a gauge length of $50 \mathrm{~mm}$. When the load reached $50 \%$ of the estimated ultimate load, the extensometer was removed to prevent it from being damaged. The dispersion failure of the fibers in the test section was considered as the effective failure mode. The elastic modulus was calculated using the load values of the limit load of $20 \%$ and $50 \%$ and the corresponding strain.
Based on GB/T 13683-92 [20], the transverse shear method was adopted to measure the shear properties, and the loading rate was $0.02 \mathrm{kN} / \mathrm{s}$. The shear failure load was recorded continuously until the shear failure of the specimen. The shear strength is calculated according to $\tau_{\mathrm{u}}=0.5 \mathrm{P}_{\mathrm{s}} / \mathrm{A}$, where $\tau_{\mathrm{u}}$ is the shear strength, $\mathrm{P}_{\mathrm{s}}$ is the ultimate capacity, and $\mathrm{A}$ is the actual cross-sectional area of the specimen [20].

\section{Results and discussion}

\subsection{Tensile strength degradation}

Figure 6 shows the tensile strength retention versus corrosion age. As shown in Figure 6, the tensile strength retention of the BDSM bars was the highest at all corrosion ages. About $90 \%$ of the tensile strength was retained at the 63rd day. The strength retention of the BMFE bars was 


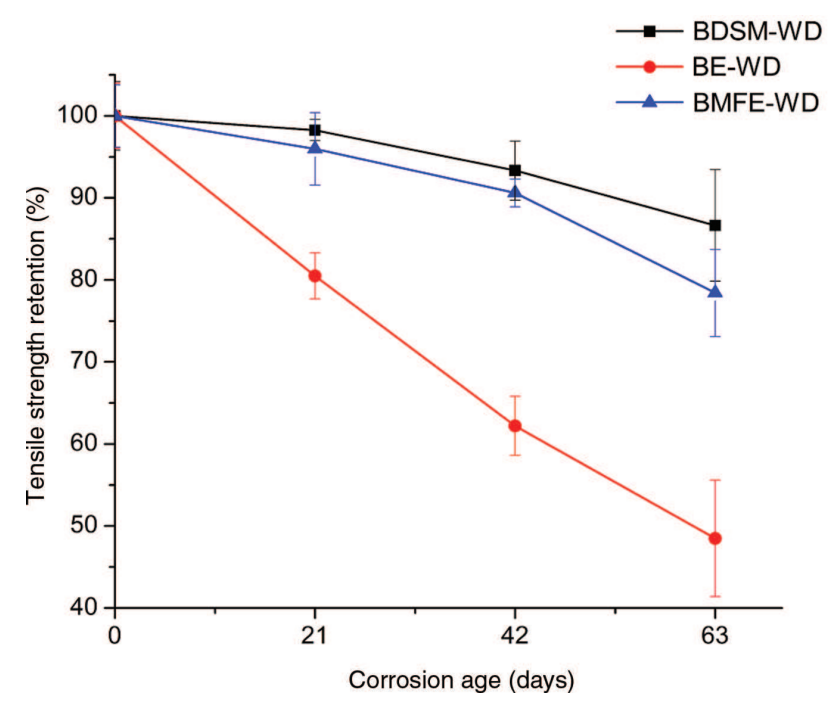

Figure 6: Tensile strength retention.

approximately $80 \%$ at the 63 rd day, which was slightly less than that of the BDSM bars. The strength retention of the BE bars was significantly lower than that of the other vinyl resin matrix BFRP bars; it was less than $50 \%$ at the 63rd day. Therefore, the BE bars exhibited the worst corrosion resistance performance, which also demonstrated that the alkali-salt corrosion resistance of the E51 epoxy resin matrix BFRP bars was more severe than that of the vinyl resin matrix BFRP bars. In the vinyl resin matrix BFRP bars, the alkali-salt corrosion resistance of the BDSM bars was superior to that of the BMFE bars. The reasons can be explained as follows.

The corrosion of FRP materials by an alkali-salt solution is mainly caused by the decreased protection of the resin on the fiber due to the permeation of water molecules. Water absorbability is related to the hydrophilic group of the resin. From the molecular formulae of vinyl and epoxy resin, there are two ester groups and two hydroxyl groups per mole of the vinyl resin, in which the ester group is protected by methyl groups and distributed at the end of the molecular chain, which has little effect on the main body of the molecular chain. In the molecular structure of vinyl resin, the cross-linking double bonds adjacent to the ester groups are cured into a 3D cross-linked network formation through the participation of styrene, and the space protection is applied on the ester base to give the vinyl resin high hydrolytic stability [21]. As a result, the vinyl resin is not highly absorbed. It contains few chemical groups to react with the alkali solution and is protected by methyl groups. Therefore, it exhibits effective properties in the alkali-salt solution.

Owing to the high reaction temperature of the acid anhydride-based curing agent in the epoxy resin, the curing rate is relatively slow. Generally, imidazole is added to acid anhydride-based curing agents as a high-temperature curing initiator. The tertiary amine and anhydride in the imidazole reacts to form carboxylate anions. The carboxylate anions open the epoxy group to produce ester bonds and produce siloxanions. The anions react with other anhydrides and generate carboxylate anions. Influenced by the accelerator, the curing reaction of the acid anhydride and epoxy resin generates ester bonds without any other bonds. The chemical equation is illustrated in Figure 7. Ester bonds are prone to alkaline hydrolysis in a strong alkaline environment, and the hydrolysis reaction is shown in Figure 8. The main resin matrix structure is

2

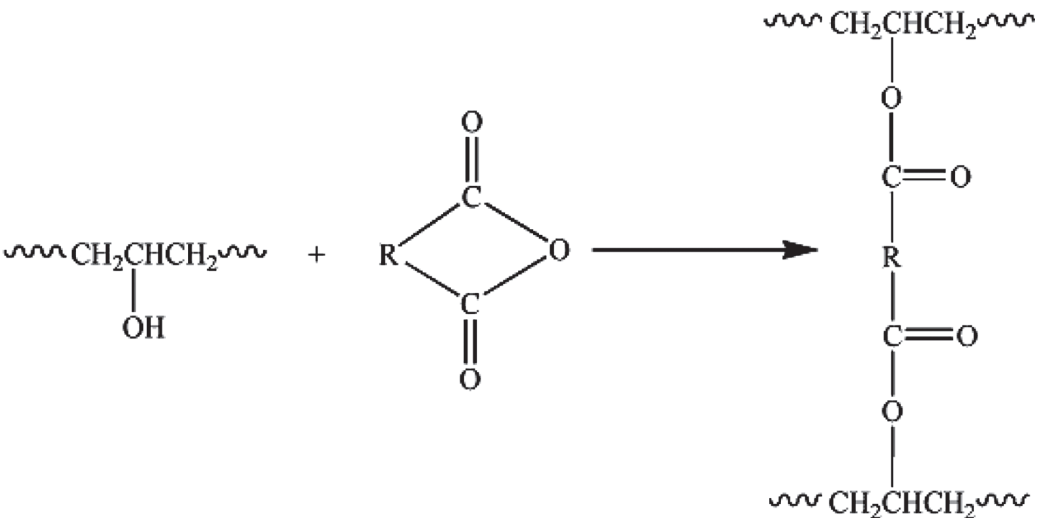

Figure 7: Curing reaction of bisphenol A epoxy resin and methyl tetrahydrophthalic anhydride.

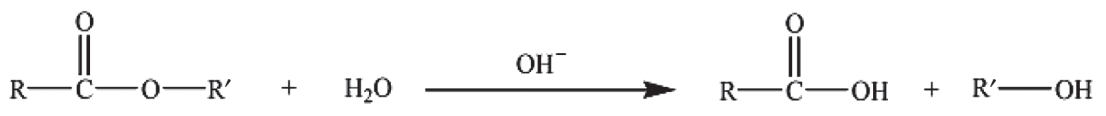

Figure 8: Alkali hydrolysis progress of ester bonds. 


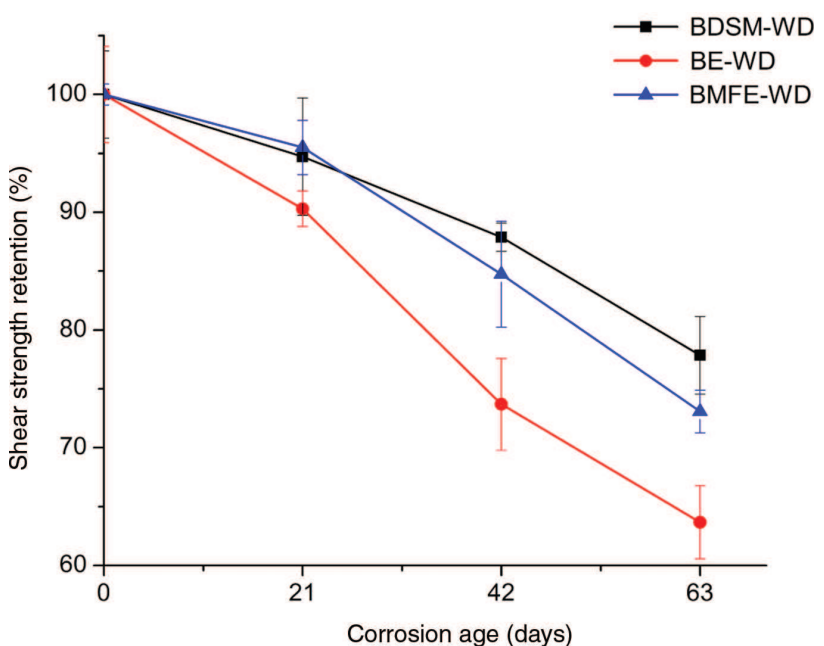

Figure 9: Shear strength retention.

destroyed and the moisture absorption rate of the resin is increased. The corrosion performance of the epoxy resin matrix BFRP bars in the alkali-salt solution is inferior to that of the vinyl resin matrix BFRP bars.

\subsection{Shear strength degradation}

The shear strength retention of the BFRP bars with respect to corrosion age is illustrated in Figure 9. As shown in Figure 9, the shear strength retention of the BE bars is significantly lower than that of the BDSM and BMFE bars through the whole corrosion age. The order of shear strength retention is: BDSM bars $>$ BMFE bars $>$ BE bars. The degradation of shear strength is similar to the degradation of tensile strength.

\section{Comparison of continuous immersion and wet-dry cycles corrosion}

\subsection{Tensile properties of BFRP bars}

The tensile strength of the BFRP bars with respect to corrosion age is illustrated in Figure 10.

As can be seen from Figure 10, the tensile strength of the same type of matrix specimens under wet-dry cycles at each corrosion age is higher than that under continuous immersion conditions, and the difference between the two corrosion conditions for the E51 epoxy resin matrix BFRP bars is larger than that of the vinyl resin matrix BFRP bars.

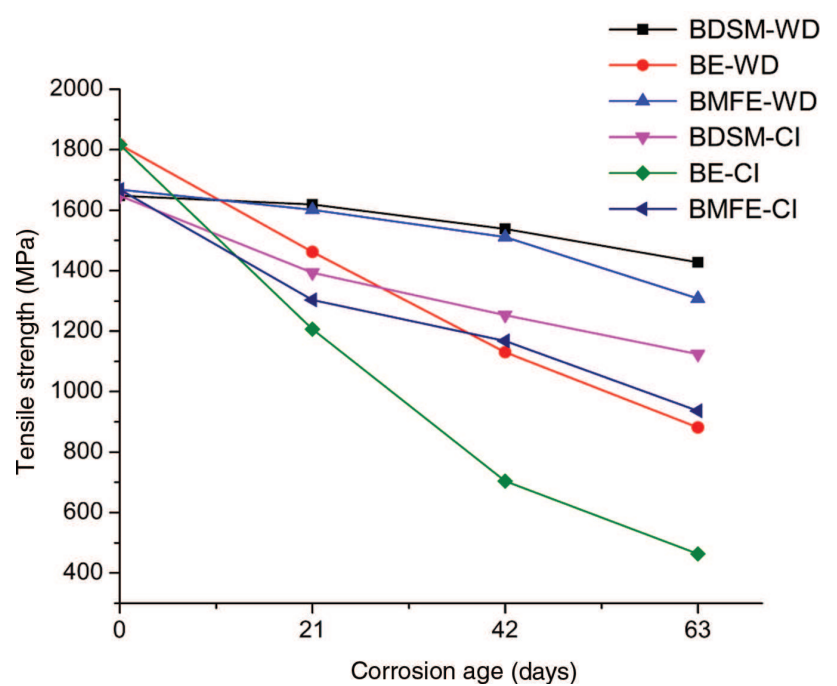

Figure 10: Tensile strength of different corrosion conditions versus corrosion age.

Table 3: Fitted results.

\begin{tabular}{lrrrr}
\hline Specimen & $\mathbf{a}$ & $\mathbf{b}$ & Correlative factor & $\mathbf{t}_{\mathbf{s}} / \mathbf{t}_{\mathbf{W D}}$ \\
\hline BDSM-CI & -26 & 117.4 & 0.93 & 4.31 \\
BDSM-WD & -26 & 133.9 & 0.93 & \\
BE-CI & -75 & 162.2 & 0.98 & 1.86 \\
BE-WD & -75 & 182.4 & 0.98 & \\
BMFE-CI & -34 & 121.9 & 0.87 & 3.93 \\
BBMFE-WD & -34 & 142.1 & 0.87 & \\
\hline
\end{tabular}

$\mathrm{Cl}$, continuous immersion; WD, wet-dry.

From Table 3, it can be seen that the differences in tensile strength of the BDSM bars, BE bars, and BMFE bars under continuous immersion and wet-dry cycles after the 63rd day of corrosion are $303.9 \mathrm{MPa}$, $418 \mathrm{MPa}$, and $371.5 \mathrm{MPa}$, respectively. This indicates that the difference increases with the decrease of alkali resistance of the FRP. The reasons can be explained as follows. In the early stage of immersion, water molecules and alkali ions are adsorbed in the surface of the BFRP bars, and then infiltrate into the fiber-resin interface layer through the resin microcracks. This infiltration is relatively slow. Under continuous immersion conditions, the corrosion reaction occurs continuously, and the corrosion effect is remarkable. In the wet-dry cycles, when the BFRP bars are dried at $55^{\circ} \mathrm{C}$ for $12 \mathrm{~h}$, the water molecules are basically removed from the bars. When the specimens are immersed in the corrosive solution, the water molecules and other ions are readsorbed. Therefore, the accumulative corrosion effect is not significant. Under continuous immersion conditions, the corrosion effect of BFRP bar is much greater than that of wet-dry cycling. 

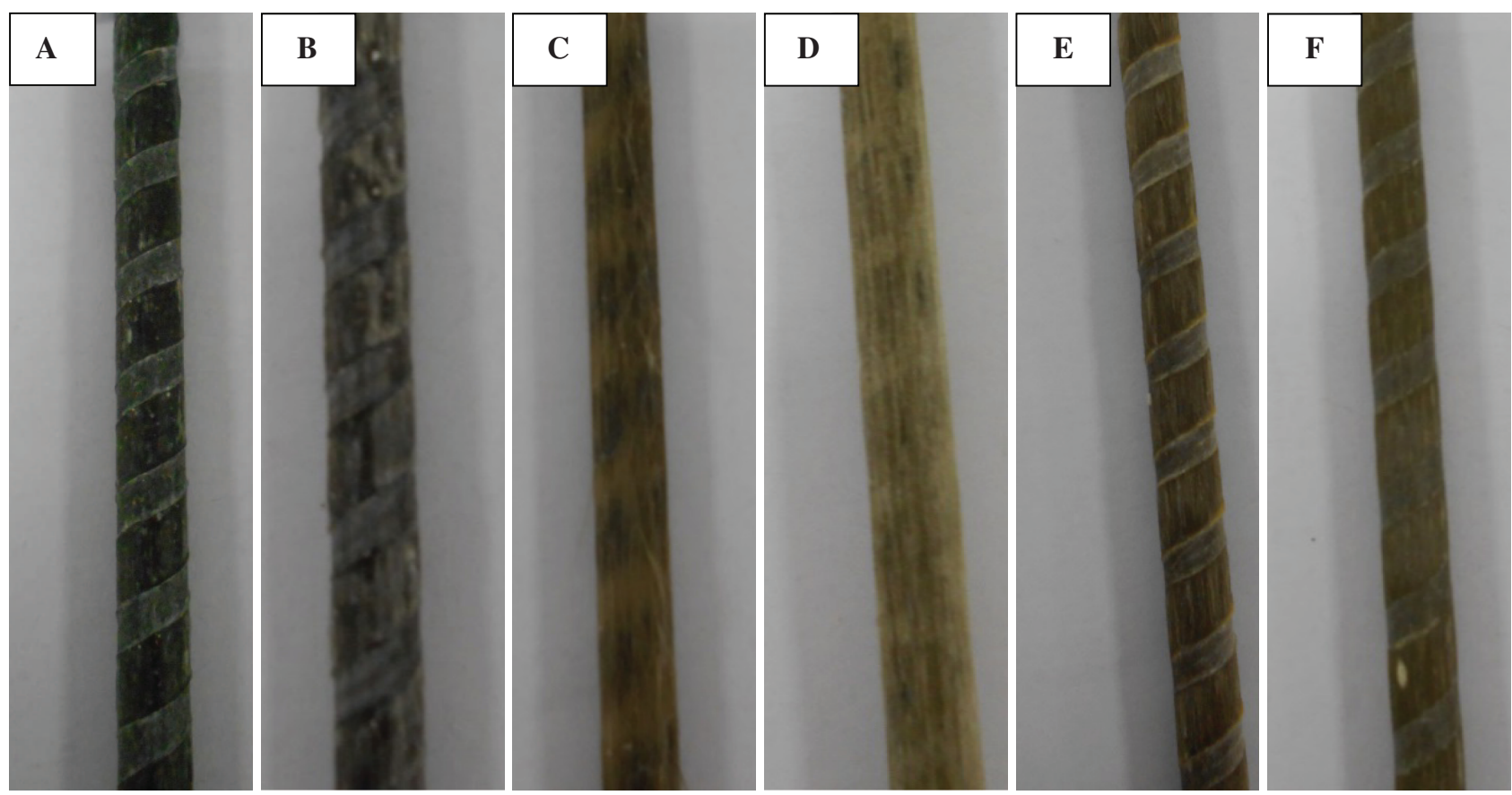

Figure 11: Appearance of basalt fiber-reinforced polymer (BFRP) bars: (A) BDSM-WD bars; (B) BDSM-CI bars; (C) BE-WD bars; (D) BE-CI bars; (E) BMFE-WD bars; (F) BMFE-CI bars. $\mathrm{Cl}$, continuous immersion; WD, wet-dry.

\subsection{Corrosion appearance and SEM images of BFRP bars}

In order to verify the corrosion mechanism of specimens with different types of matrix resin under different corrosive conditions (wet-dry cycle or continuous immersion), specimens aged for 63 days were studied by SEM. The results are illustrated in Figures 11 and 12.

As can be observed from Figure 11, in view of the appearance, the corrosion degree of the BFRP bars under the wet-dry cycles is slighter than that under the continuous immersion conditions, particularly for the BE bars, which exhibit fiber color after continuous immersion. This demonstrates that the alkali-salt resistance performance of the BFRP bars under the wet-dry cycling is better than that under continuous immersion conditions.

In Figure 12A, few cracks are observed in BDSM bars under wet-dry cycling. However, there are several small cracks in the BDSM bars after continuous immersion, as shown in Figure 12B. This demonstrates that the corrosion degree of continuous immersion is more serious than that of wet-dry cycling. Similar phenomena are also observed in the BE and BMFE bars. Moreover, the longitudinal cracks propagate and connect with each other on the surface of the epoxy resin matrix BFRP bars and are wider than those of the vinyl resin matrix BFRP bars.

\section{Conversion relationship between wet-dry cycles and continuous immersion}

Bank et al. [22] found that the FRP strength retention is linear with the logarithm of the corrosion age. This relationship can be described as $\mathrm{Y}=\operatorname{alog}(\mathrm{t})+\mathrm{b}$, where $\mathrm{Y}$ is the strength retention, $t$ is the corrosion age, and $a$ and $b$ are the fitted parameters. In this study, we attempted to establish the time transition relationship between the two corrosive conditions.

As shown in Figure 13, the experimental data of the strength retention of the BFRP bars are fitted. The fitted lines are approximately parallel to each other, and $t_{S}$ and $t_{D W}$ are defined as the continuous immersion and wet-dry cycle corrosion age, respectively. Because $\log \left(\mathrm{t}_{\mathrm{S}}\right)-\log \left(\mathrm{t}_{\mathrm{DW}}\right)$ is a constant value, $t_{S} / t_{D W}$ is also a constant. The fitted results are displayed in Table 3.

For the vinyl resin matrix BFRP bars, the corrosion degree of continuous immersion for 1 day in a certain aging time is equivalent to that of wet-dry cycle corrosion for about 4 days. For the epoxy resin matrix BFRP bars, the extent of continuous immersion corrosion for 1 day is equivalent to that of wet-dry cycle corrosion for 1.86 days. Using the above conversion relationship, the durability of the BFRP bars under natural tide action could be easily 

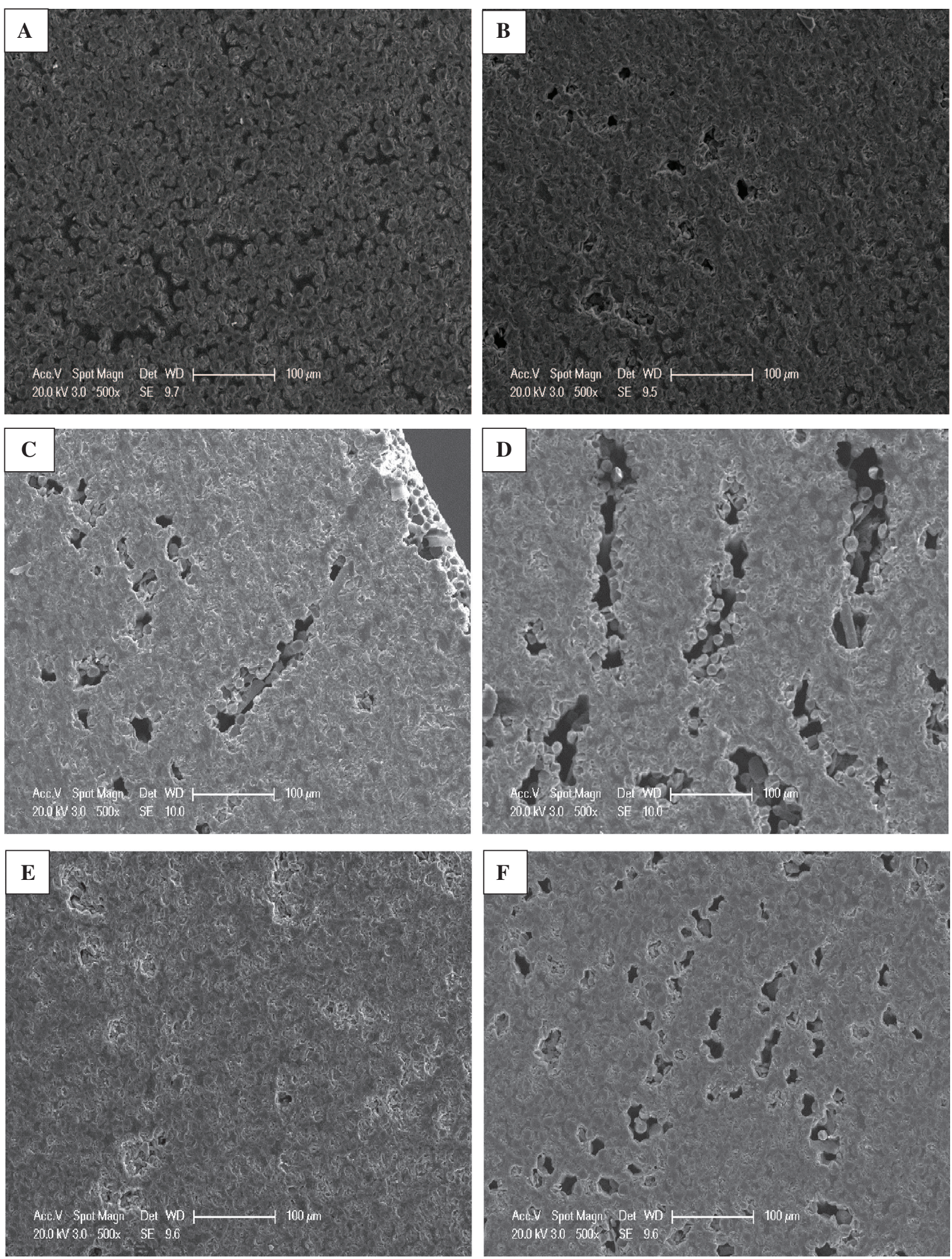

Figure 12: Scanning electron microscopy (SEM) images of basalt fiber-reinforced polymer (BFRP) bars: (A) BDSM-WD bars; (B) BDSM-CI bars; (C) BE-WD bars; (D) BE-Cl bars; (E) BMFE-WD bars; (F) BMFE-Cl bars. $\mathrm{Cl}$, continuous immersion; WD, wet-dry.

obtained by means of continuous immersion experimental results. It is noteworthy that the conversion relationship in this study is a preliminary exploration, based on the same dry and wet times. If the dry and wet times are different, the results may change, and further experimental data are still required to support the conversion relationship. 

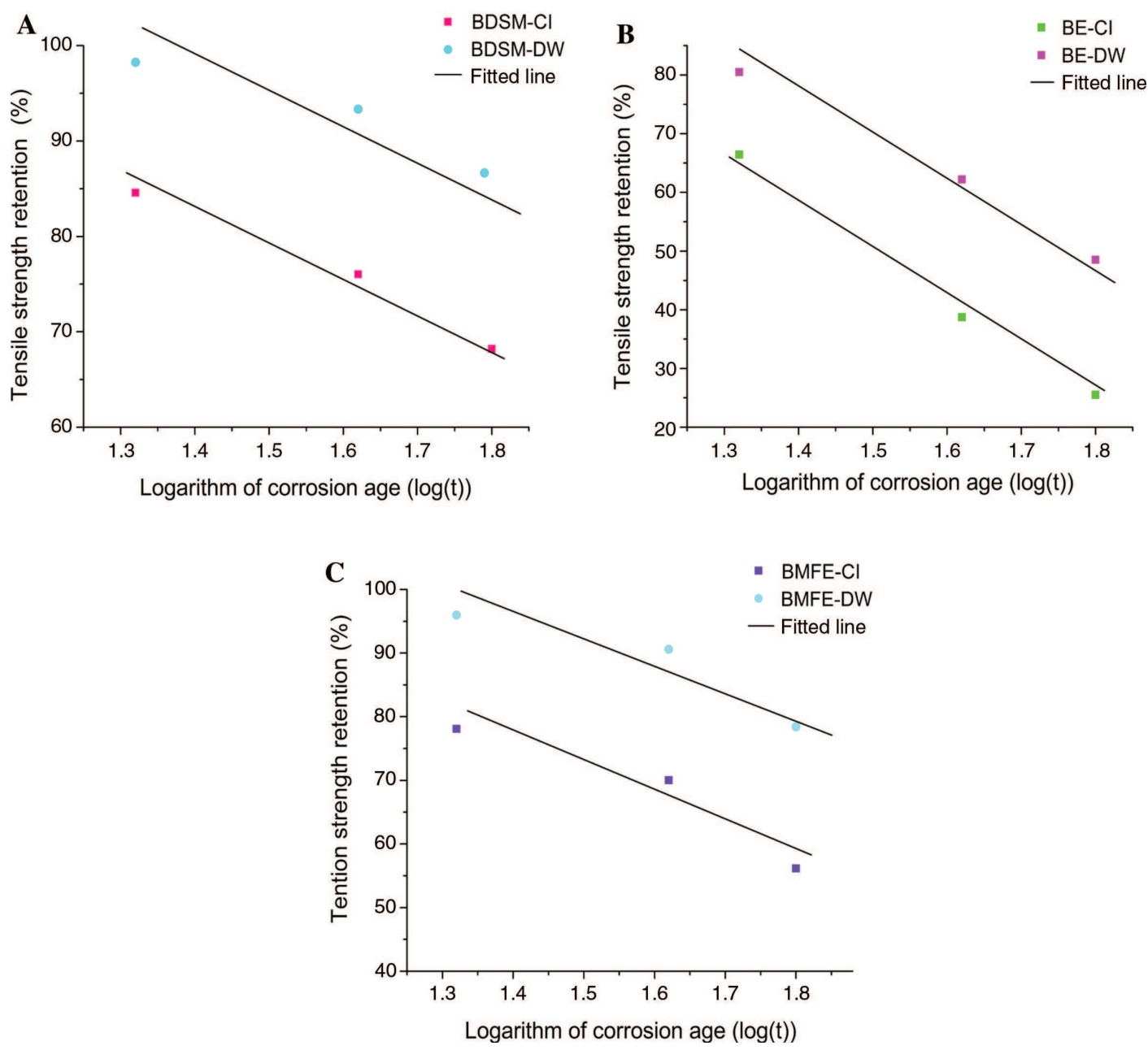

Figure 13: Fitted curves for degradation of fiber-reinforced polymer (BFRP) bars: (A) fitted curves for BDSM bars; (B) fitted curves for BE bars; (C) fitted curves for BMFE bars.

\section{Conclusions}

In this study, the tensile and shear properties of BFRP bars were tested by wet-dry cycling under the conditions of alkali-salt corrosion. Another continuous immersion test was implemented as a comparison. The corrosion mechanisms of the BFRP bars with different types of resin matrix under different immersion conditions were clarified. Furthermore, time shift factors were proposed to predict the durability of the BFRP bars aging under wet-dry cycles according to the continuous immersion data. The following conclusions can be drawn.

(1) Under the wet-dry cycles, the tensile and shear properties of the BFRP bars decreased significantly under alkali-salt solution at $55^{\circ} \mathrm{C}$. The alkali-salt resistance of the vinyl resin matrix BDSM bars was obviously superior to that of the epoxy resin matrix BE bars. The tensile strength retention of the BDSM bars aged for
63 days was $38.16 \%$ higher than that of the BE bars, and the shear strength retention of the BDSM bars aged for 63 days was $14.18 \%$ higher than that of the BE bars.

(2) The corrosion rate under the wet-dry cycles was obviously slower than that under continuous immersion. During one wet-dry cycle, when the bars reentered the corrosion solution, the water molecules and hydroxide ions were re-adsorbed and intruded into the bars. Thus, the accumulation of the corrosion effect was not obvious.

(3) The continuous immersion method is an effective laboratory simulation method to predict the wet-dry cycles. The preliminary analysis demonstrates that, in order to convert the corrosion age of continuous immersion into that of wet-dry cycling, the time-shift factors for the vinyl resin and epoxy resin matrix BFRP bars were 4 and 1.86, respectively. 
Acknowledgments: The authors gratefully acknowledge the financial support provided by the National Key R\&D Program of China (Grant No. 2017YFB0310904).

\section{References}

[1] Issa MS, Metwally IM, Elzeiny SM. Compos. Struct. 2011, 33, 1754-763.

[2] Hollaway LC. Constr. Build. Mater. 2010, 24, 2419-2445.

[3] Soutis C. Mater. Sci. Eng. A 2005, 412, 171-176.

[4] Bakis CE, Bank LC, Brown VL, Cosenza E, Davalos JF, Lesko JJ, Machida A, Rizkalla SH, Triantafillou TC. J. Compos. Constr. 2002, 6, 73-87.

[5] Davalos JF, Chen Y, Ray I.J. Compos. Mater. 2012, 46, 1899-1914.

[6] Elsafty A, Benmokrane B, Rizkalla S, Mohamed HM, Hassan M. BDK82-977-05, 2014.

[7] Benmokrane B, Elgabbas F, Ahmed EA, Cousin P. J. Compos. Constr. 2015, 19, 1-12.

[8] Elgabbas F, Vincent P, Ahmed E, Benmokrane B.Compos. Part B 2016, 91, 205-218.

[9] Wang ZK, Yang ZH, Yang YM, Xian GJ. Polym. Compos. 2016, 39, 1731-1741.

[10] Wu ZS, Wang X, G Wu. Advancement of structural safety and sustainability with basalt fiber reinforced polymers. The
Sixth International Conference on FRP Composites in Civil Engineering, 2012.

[11] Elgabbas F, Ahmed EA, Benmokarane B. Constr. Build. Mater. 2015, 95, 623-635.

[12] Xie Y, Guan KH, Lai L. Int. J. Polym. Sci. 2016, 2016, 1-7.

[13] Zhou JL, Xu CX, Jiang SY. Mater. Des. 2013, 284-286, $182-186$

[14] Lu ZY, Xie JH, Zhang H. Polymers 2017, 9, 652.

[15] Serbescu A, Guadagnini M, Pilakoutas K.J. Compos. Constr. 2015, 19, 04014037.

[16] Wu G, Wang X, Wu ZS, Dong ZQ, Xie Q. Sci. Eng. Compos. Mater. 2015, 22, 649-657.

[17] Al-Salloum YA, El-Gamal S, Almusallam TH, Alsayed SH, Aqel M.Comp. Part B 2013, 45, 835-844.

[18] ACl Committee 440. Guide Test Methods for Fiber-Reinforced Polymers (FRPS) for Reinforcing or Strengthening Concrete Structures. $\mathrm{ACl}$ 440.3. American Concrete Institute: USA, 2004.

[19] Wu G, Dong ZQ, Wang X. J. Compos. Constr. 2015, 19, 04014058.

[20] ASTM D3914. Standard Test Method for In-Plane Shear Strength of Pultruded Glass-Reinforced Plastic Rod, ASTM International: West Conshohocken, PA, USA, 2002.

[21] Suvorova AI, Tyukova IS, Suvorov AL, Sobenina ME. Polym. Sci., Ser. A 2015, 57, 315-320.

[22] Bank LC, Gentry TR, Thompson BP, Russel JS. Constr. Build. Mater. 2003, 17, 405-437. 